To cite this article: Luigi E. Balucan, Mary Conie T. Sanico and Peter Xureen S. Ponce and Jennifer B. Cabaron (2021). STRESSOR AND COPING STRATEGIES AMONG ACCOUNTANCY STUDENTS DURING COVID-19 PANDEMIC, International Journal of Research in Commerce and Management Studies (IJRCMS) 3 (6): 145-173

\title{
STRESSOR AND COPING STRATEGIES AMONG ACCOUNTANCY STUDENTS DURING COVID-19 PANDEMIC
}

\author{
Luigi E. Balucan, Mary Conie T. Sanico and Peter Xureen S. Ponce and Jennifer B. Cabaron \\ Jose Rizal Memorial State University, Dapitan City, Philippines
}

DOI: http://dx.doi.org/10.38193/IJRCMS.2021.3610

\begin{abstract}
The study's main objective was to determine stressor and coping strategies among accountancy students of Jose Rizal Memorial State University, Main Campus, during the COVID-19 pandemic. The study utilized descriptive qualitative research methodology in collecting relative information. A purposive sampling technique was utilized in determining the research participants. The researcher's primary data gathering tool is a Semi-Structured Interview (SSI). Additionally, the study used the thematic approach in the analysis and interpretation of data. Major findings of the study showed that environmental stressors such as unstable internet connection, family activities, and problems and isolation due to health protocols contribute to students' stress. Another stressor that triggers anxiety is the academic factors: modular distance learning - there is no face-to-face discussion, early submission of activities and assessments, lack of immediate response from instructors, and psychological stressor: lack of self-discipline. On the other hand, despite the existing stressors, students adopted task-oriented coping strategies like using two different networks and double data in case of unstable internet connection, observing time management, learning to adjust to the environment, and finding other ways to contact instructors. The second coping strategy used was emotion-oriented coping strategies such as self-realization, self-meditation, and self-motivation. Thus, the researchers affirm that the study's findings are similar to the transactional theory of Lazaro and Folkman that when the accountancy students faced challenges, they were stressed and negatively affected.
\end{abstract}

KEYWORDS: Stressor, Coping Strategies, COVID-19 Pandemic

\section{INTRODUCTION}

The coronavirus 2019 (COVID-19) outbreak, reportedly began in China in December 2019, has become a global disaster that has spread quickly. To stop the spread of the disease, practically every country has implemented public health measures. According to the United Nations Educational, Scientific, and Cultural Organization (UNESCO) 2020, the pandemic has affected the studies of more than one billion kids in 129 countries throughout the world. Many colleges throughout the world have turned to emergency remote teaching (ERT) using online platforms, which has increased student 
stress. With in-person classes impossible, the Commission on Higher Education (CHED), which administrates colleges and universities, put together distance learning options that include online platforms, offline modules, or a combination of the two, called blended or flexible learning.

According to Obbarius, Fischer, Liegl, et al. (2021), Lazarus defined stress as a relationship between a person and their environment that they perceive as exhausting or beyond their resources, putting their well-being at risk. It is best viewed as an interpretative paradigm between the stressors and the individual's psychological reactions. Nor, Nahar, Algazi, Taha (2019) cited Uehara, Takeuchi, Kubota (2010), stress is common among students in higher education institutions, owing to the necessity to adapt to various psychosocial changes and cope with the academic and social demands of their particular professions. Some of the causes of stress suggested include meeting grade requirements, test-taking, the volume of materials to be learned, and time management (Beiter et al., 2015).

Stress has a negative impact on student life and academic achievement. However, except for Gabre and Kumar (2012) and How, Shinde, and Willems (2013), a limited number of studies specifically investigated the level of stress faced by accounting undergraduate students. Accounting has been increasingly a popular choice among students to pursue their tertiary education, aligning with the national aspiration to produce 60,000 professional accountants by 2020 (Bernama, 2015). According to Kapasia, Paul et al. (2020), in "India Today," there are three major education problems students and educators currently face due to the Covid-19 pandemic: 1 . Students caught in the crosswire. These students are caught in limbo on account of education outcomes being withheld due to the Covid19 pandemic. Some students do not have a result since tests were either canceled or postponed. 2 . Students that are one year away from finishing high school or college. 3. Disruption in the educational system. Many schools and universities have gone online due to the Covid-19 threat, and parents appear to have taken on teachers' jobs.

Coping strategies to reduce stress are necessary for preventing the harmful effects of prolonged stress (William et al., 2010). Coping strategies are the methods people employ to master, decrease, or eliminate unpleasant situations. Coping strategies may be seen as both negative and positive and maybe problem-focused or emotion-focused (Bond \& Bunce, 2000; Folkman \& Lazarus, 1988; Gruen, Folkman, \& Lazarus, 1988). According to Anspaugh and colleagues, coping with stress means attempting to manage or deal with stress, and coping does not necessarily result in success. Amirkhan and Auyeung (2007) agreed to the assertion that coping does not necessarily imply success with dealing with the stressor. Myers and Rothblum, E. D. (2005). also defined coping strategies as to how a person reacts or responds to a stressor.

Along with this underlying fact, the researchers deemed it considerably to determine the stressor and 
coping strategies among accountancy students of Jose Rizal Memorial State University-Main Campus, Dapitan City, during the COVID-19 pandemic. The result of the present study may have implications on the college life of accounting students; provide helpful information for teaching and counseling services, and ultimately assist in optimizing the academic potential of this particular student group, especially in times of global pandemic. As a result, this study aims to add to the current literature by objectively evaluating the effects of the COVID-19 epidemic on accountancy students' reported stress during the peak of the pandemic. It should also give policymakers advice on how to mitigate the impact of stress on pupils during a crisis. Further, research is proposed to include successful coping strategies used by the students during testing times, such as the COVID-19 pandemic.

\subsection{REVIEW OF RELATED LITERATURE}

As cited in Biggs, Brough, and Drummond, this study was based on Lazarus and Folkman's (1987) Transactional Theory of Stress and Coping, which depicts stress as a transaction between a person (including multiple systems: cognitive, physiological, affective, psychological, and neurological) and their complex environment. As defined by Lazarus and Folkman, stress coping is a more particular process of cognitive evaluation that determines whether an individual believes they can effectively adapt to the demands of a stressor or change (see Figure 1). (Folkman \& Lazarus, 1988; Lazarus \& Folkman, 1987). Similarly, according to Oyewobi, L. O., Bolarin, et al. (2020) cited Lazarus and Folkman (1984), stress is a key subject in the social sciences, particularly in behavioral studies, and in research that focuses on the study of life. The uniqueness of stress could be seen between an individual and the environment in which the person resides, resulting in the lack or excess of their involvement, which might put their well-being at risk. 


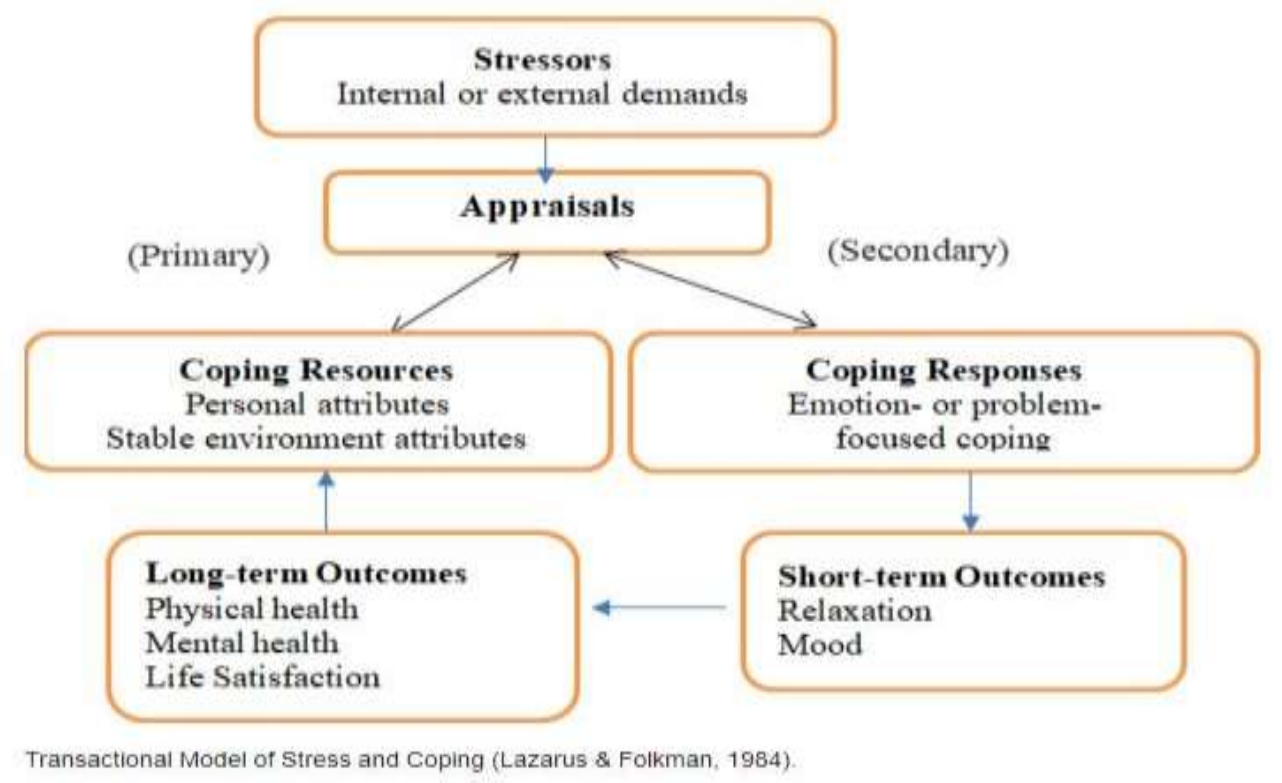

Figure 1. The Theoretical Framework of the Study

Furthermore, this research was based on Kwaah \& Essilfie's (2017) concept at the University of Cape Coast, Ghana, titled "Stress and Coping Strategies among Distance Education Students. 'High academic workload' was the highest mean among the academic-related stressors, showing that academic work caused a lot of stress for distance education students. This is followed by 'frequent examinations' and 'poor examination performance. 'According to Reddy, Menon, and Thattil (2018), stress is considered a part of student life, owing to many personal, family, and contextual expectations. Other authors suggest that, while stress is present among all students because of their workloads, adolescent students are more vulnerable to academic stress due to changes in their lives both personally and socially.

Coping strategies utilized more than once by learners to minimize stress levels include effectual time management, social help, constructive reassessment, and commitment in comfortable interests (Ahmadi, Khodayarifard, Zandi, et al., 2018). A study by Yusoff (2010) revealed that the top five coping strategies that students frequently used were religion, active coping, positive reinterpretation, planning, and the use of instrumental support. Accordingly, this research was premised on the fact that stressors can trigger coping responses for Accountancy students.

\subsection{METHODOLOGY}

This study utilized the descriptive qualitative research methodology in gathering the information needed. This method was used because the researcher wanted to provide a detailed discussion of the 
meaningful experiences that determined the stressor and coping strategies among accountancy students of Jose Rizal Memorial State University, Main Campus, Dapitan City, during the COVID-19 pandemic of the academic year (A.Y.) 2020-2021. All data sets gathered focused on the stressor and coping strategies among accountancy students. The major contribution of this research is to draw a recommendation that will aid students in reducing the impact of stress during such a situation.

The participants of this study were the college students of JRMSU taking up Bachelor of Science in Accountancy in the different year level. The students are purposefully selected to participate in this study to assure that only the institution and the accountancy students are used as the study's participants. The researcher utilized a purposive sampling method to determine the participants of the study. In this method, the researchers have already known and identified the participants as students taking up Bachelor of Science in Accountancy at JRMSU - Main Campus.

The participants of this study were the ten (10) Accountancy students out of a total population of 360 who will participate and answer the questions in the virtual interview via zoom. Table 1 presents the distribution of respondents of the study by year level.

Table 1. Distribution of Respondents

\begin{tabular}{lll}
\hline Year Level & Frequency & Percentage \\
\hline First Year & 1 & 10.0 \\
Second Year & 3 & 30.0 \\
Third Year & 6 & 60.0 \\
Total & 10 & 100.00 \\
\end{tabular}

The researcher's primary data gathering tool is an interview guide questionnaire. The Semi-Structured Interview (SSI) employs a blend of closed and open-ended questions, often accompanied by followup why or how questions (Steel, Diezel, et al., 2020).). More specifically, the instrument was Interview Guide Question based on the research questions. This interview follows a sequence. In the first topic of the interview, the respondents were asked about their demographic profile such as age, gender, year level, and home location. The second topic of the interview focused on the stressors of the students during the COVID2-19 pandemic. The last issue of the interview deals with the coping strategies adopted by students. Participants are asked about their ways to cope-up with their stress during the COVID-19 pandemic.

This study utilized the thematic approach of Braun and Clarke (2006) in the analysis and interpretation 
of data. The interview analysis was done manually by the researchers. Braun and Clarke (2006) described that the phases of thematic analysis allow for a systematic way of seeing and processing qualitative information using coding.

The first phase is data familiarization, which involves transcribing the data, reading and re-reading the data, and noting the initial ideas. Central ideas were highlighted and written down for each transcript. The second phase is generating the initial code. Coding interesting data features in a systematic fashion across the entire data set, collecting data relevant to each code (Braun and Clarke 2006). Features were coded as a brief-phrase or keyword indicating a single notion while translating and transcribing.

The third phase is the searching for themes across the data. Collating codes into potential themes, gathering all data relevant to each possible theme (Braun \& Clarke 2006). The data were read and reread, and the cycle was repeated several times to narrow down the number of codes and categorize them into identifiable themes. The content of the data directs coding and theme generation. The codes were then analysed and grouped into themes to answer the study's central questions. The fourth phase reviews the themes and checks if the themes work with the coded extracts at the first level and then the entire data set at the second level (Braun \& Clarke 2006). To ensure that the codes were correct, the researcher read the whole interview data. The fifth phase is producing the report. The researcher extracted several statements representing the data to showcase the resulting outcomes in the form of ideas. The researchers facilitate this strategy after the data gathering procedure. Further, the data were treated and interpreted according to the stated problems' chronology. The researchers examined the collected data in light of the reviewed literature and theoretical framework.

\section{ETHICAL CONSIDERATION}

The researchers determine the stressor and coping strategies among accountancy students of Jose Rizal Memorial State University-Main Campus during the COVID-19 Pandemic. The ethical consideration was presented by securing the transmittal letter from the researcher's adviser and an invitation letter to the participants to achieve the objectives of the study. The researchers gathered the data needed by the study gathered through a virtual interview with the purposely selected participants. To guarantee each participant's information privacy, the researcher sent different zoom meeting link to their respective Facebook account. Participants' answers to the interview questions were treated with confidentiality and professionalism.

Furthermore, the researchers did not disclose the names of the participants in the presentation of data. Their participation is voluntary, and there was no corresponding penalty in case of a pullback from the interview. Hence, there are no anticipated risks from participating in this study. Furthermore, the association of the participants in this study was to respond to achieve the study's main objectives. The 
result is assured to incorporate truthfulness through the entire process.

\subsection{RESULTS AND DISCUSSION}

Table 2. Demographic Profile of the Respondents

\begin{tabular}{llll}
\hline & Profile & Frequency & Percentage \\
\hline & 18 & 1 & $10 \%$ \\
Age & 20 & 1 & $10 \%$ \\
& 21 & 6 & $60 \%$ \\
& 22 & 2 & $20 \%$ \\
& Total & 10 & $100 \%$ \\
& Male & 3 & $30 \%$ \\
Gender & Female & 7 & $70 \%$ \\
& Total & 10 & $100 \%$ \\
& & & \\
Year & 1st year & 1 & $10 \%$ \\
Level & 2nd & 1 & $10 \%$ \\
& 3rd year & 8 & $80 \%$ \\
& Total & 10 & $100 \%$ \\
Home & & & $30 \%$ \\
Location & Rural Areas & 3 & $70 \%$ \\
& Urban Areas & 7 & $100 \%$ \\
\hline
\end{tabular}

Presented in Table 2 is the demographic profile of the respondents as to age, gender, year level, and home location. Among the ten respondents, 1 or $10 \%$ were 18 years old, 1 or $10 \%$ of the respondents were 20 years old, 6 or $60 \%$ belonged to 21 years old, and about 2 or $20 \%$ were 22 years of age. In terms of gender, the majority $(70 \%)$ of the respondents were female, while 3 or $30 \%$ were males. Females express emotions to a more significant extent than males, according to a study done in Malaysia (2020), and the recent pandemic may have aggravated this condition. According to studies, women's uncertainty tolerance thresholds are lower than men's, causing unnecessary stress. In uncertain and stressful settings, female students may have fewer coping methods than male students (Sundarasen et al., 2020). When it comes to year level, many respondents, or $80 \%$, were third-year accountancy students, and both $10 \%$ were first and second-year students. In terms of home location, most $(70 \%)$ of the respondents were living in urban areas, and the remaining $30 \%$ were from remote areas. 
Table 3 Stressors of BS-Accountancy Students during COVID 19

\begin{tabular}{ll}
\hline Stressors & Responses \\
\hline \multirow{3}{*}{ Environmental } & Unstable internet connection \\
& Family activities and problems \\
& Isolation due to health protocols \\
& Modular Distant Learning- there is no face-to-face \\
& discussion \\
Academic & Early submission of activities and assessment \\
& Hardly have a response from instructors \\
& \\
& \\
& Lack of self-discipline \\
\end{tabular}

The researchers considered this theme an essential aspect in the learning process during a pandemic because it determines the perceived stress of the learners. These themes have two sub-themes, namely, Environmental Stressors, Academic Stressors, and Psychological Stressors.

1. Environmental Stressors. Environmental Stressors sub-theme is divided into (a) Unstable internet connection (b) Family activities and problems (c) Isolation due to health protocols.

\subsection{Unstable internet connection}

Two out of the ten participants said that having an unstable internet connection was a source of their stress. They stated that they were stressed as a result of the unstable internet connection. The following statements accurately reflect their emotions:

\section{Participant 1:}

In terms of my academics, WIFI's unstable internet connection made me stress

\section{Participant 2:}

In this time of the pandemic, there were times where there is a loss of internet connection.

Participants one and two stated that they got stressed because of their WIFI's and unstable internet connections. These resulted in the delay in submitting their activities and assessments. Participant one added that it also affects his virtual meetings and online announcements. Rotas et al. (2020) highlighted the unpredictable internet availability as one of the most significant obstacles respondents' experiences when practicing remote learning. The poor networks are prevalent in poorer countries 
when telecommunication systems and ICT are underdeveloped (Aboagye et al., 2020). Even though the country offers a variety of internet packages, they are "fluid" and not manufactured in the same way in terms of speed and stability (Amadora, 2020).

Furthermore, Sundarasen et al., 2020 discovered that the students had challenges in terms of technological infrastructure, particularly a bad internet connection. A nationwide cross-sectional study reported that twenty-two percent (22\%) out of 3670 Filipino medical students surveyed do not have reliable internet access (Baticulon et al., 2020). For some, it may present difficulty to purchase a facilitative learning device to quickly tune in to online classes and immediately turn in assignments in the online system (Santos, 2020).

\subsection{Family activities and problems}

Under this category, participants shared the same answer stating family activities and problems as their stressors. This affects their learning process while at home.

\section{Participant 2:}

Before the pandemic, my life as a student was more convenient because I stayed at my boarding house. Unlike now, I am studying at home because of the modular distant learning, and it is not the best place to have my school works. Household chores, family conflicts, and other activities distracted me and affected my learning process.

\section{Participant 9:}

family issues

Participant two found it difficult to study from home during this pandemic, as opposed to her last year's setup, which consisted of face-to-face seminars, and she rented a boarding house where she had a quiet area to study. Furthermore, household responsibilities were mixed in with schoolwork she is finding it difficult to concentrate on her studies. Additionally,

\section{Participant 6:}

I believe that the home cannot serve as a learning environment compared to a school since all activities may have become disorganized). Participant nine also shared the same experience with the two other participants.

As duly supported by Rotas et al.'s (2020) study, a poor learning environment is detrimental for students to participate in remote learning comfortably. Establishing a positive and conducive learning space has long been a problem in distance education, especially in most poor households (Baticulon et al., 2020). 
A significant stressor, in this case, may be the work-family role conflict (Hammer and Thompson 2003). If this problem occurs, study productivity and the utmost concentration of students are at stake (Chang \& Fang, 2020). The sudden migration to remote learning in the middle of a health crisis has overlooked an unconducive learning environment, affecting students' performance. It was clear that spending more time at home did not always imply more time for academic work. Some students could not concentrate because they were constantly exposed to conflict among family members (Baticulon et al., 2020).

Furthermore, students have expressed the difficulty of remote study schedules conflicting with their home duties. This type of disturbance is common in remote learning since students are required to help with household tasks. This issue may have an impact on the academic achievement of university students. Previous research has found that students' participation in family tasks has a negative effect on their academic performance (Poncian, 2017; and Amali, Bello \& Adeoye, 2018).

\section{Participant 4:}

I got stressed with the noise in my environment since I have a lot of nephews who love to play at our house. It is preferable to study in a calm environment, but this was extremely difficult for me to achieve, and I became stressed as a result.

\section{Participant 5:}

I got distracted by the noise around me.

\section{Participant 6:}

I got stressed by the noise of my environment.

According to participant four, because she has two nephews, the environment in their house is stressful for her. She prefers peaceful surroundings as a student. Her nephews used to make noise at their residence, making it difficult to concentrate on her schoolwork.

Learning environments, according to Ginosyan, Tuzlukova, and Hendrix (2019), are crucial to student performance. Seating, light, noise, and even color can all affect one's ability to study. Students who learn in a good setting are more motivated, engaged, and have better overall learning abilities. Students learning under unfavorable conditions, such as those that are uncomfortable, noisy, or full of distractions, will have a considerably more difficult time processing information and being engaged. 


\subsection{Isolation due to health protocols.}

One respondent found it exhausting to stay at home and not go out which is far from usual. She stated:

\section{Participant 2:}

One respondent found it exhausting to stay at home and not go out, which is far from usual. She stated:

Of course, I can't go out due to the pandemic and need to stay at home, which triggers stress.

She added that it's difficult for her to feel that way when she's bored and can't go out for a few months due to work and studying at home. She used to relax after a long day at work, but today, regardless of how exhausted she is, she was unable to take a walk due to tight health protocols and the threat of Covid-19.

The students questioned by Rotas et al. (2020) revealed that they were dealing with mental health issues. Building and maintaining excellent mental health requires the development of rapport and the maintenance of relationships. Unfortunately, the COVID-19 pandemic has caused a "social recession" (Sundarasen et al., 2020), which has resulted in long-term social distancing practices, making emotional assistance complex at this time. This problem was raised further in research (Tandon, 2020; Rajkumar, 2020; and Baticulon et al., 2020), which found that COVID-19-related mental health disorders, such as depression and stress, were related, and anxiety had an impact on students' motivation in online learning.

\section{Academic Stressors}

The academic stressor sub-theme is divided into:

- Modular Distant learning wherein there is no face-to-face discussion.

- $\quad$ Early submission of activities and assessment.

- $\quad$ Lack of immediate response from instructors.

\subsection{Modular Distant learning wherein there is no face-to-face discussion}

Due to the shift in the education system from face-to-face classes to modular distance learning, respondents expressed that it was challenging to learn with this mode. This mode of learning is new to them. This way of learning is similar to self-study and is difficult to understand. There is no interactive physical discussion, so you need to rely on everything to yourself, so it will be difficult for them as they were not used to it. The statements below supported their arguments.

\section{Participant 1:}

The way of learning now is like self-study 


\section{Participant 3:}

It is new to me since there is no face-to-face class.

\section{Participant 4:}

Now, there is no physical discussion so you need to rely everything to yourself. Now since we are in the middle of the pandemic, we adapted the Modular Distant Learning. Then, before the pandemic, I hardly understood discussions more now that there was no physical discussion. It is tough for me.

As published by Rotas et al. (2020), their findings showed that vague learning content has also become problematic. According to them, this does not stem from the delivery mode but from the content itself. Even though university teachers launched online classes, the majority of them continued to employ on-campus learning resources. For example, students are given a syllabus and modules. However, some instructions in these materials are unclear and are not attainable for an online learning setup. This may also stem from teachers' lack of experience in remote learning (Chen et al., 2020), thus giving them a hard time producing appropriate supplementary materials specifically designed for online teaching platforms (Burgess \& Sievertsen, 2020).

\section{Participant 5:}

Many factors contribute to my stress during a pandemic. One of those is my education because of the shifting of this mode of learning from face-to-face.

Another respondent added that the course now is more complicated. According to participants one and two, the subject itself is difficult to understand, which has caused them stress. According to respondent 1 , the course is challenging, especially if the grading system gets stricter. It is hard to comprehend one accounting course the more if there are several, respondent two added. The statements below represent their feelings appropriately:

\section{Participant1:}

My courses are even more difficult if my instructors will tighten the rules.

\section{Participant 2:}

I have many courses enrolled, and it takes time to learn each.

According to the literature, academic subject challenges have a more significant impact on students' stress levels and severity. It refers to the academic subject's difficulty level, which is derived from its complexity level, which is usually related to the subject's technical components. It has been suggested 
in the literature that a high subject's difficulty level effectively necessitates a high level of student comprehension capacity in grasping the subject matter, resulting in a direct impact on students' stress levels (Bruhn et al., 2002).

Furthermore, the academic load has been linked to increased stress among students in the literature. The required knowledge base and the time available to create it are unrivaled (Carveth, Gesse, \& Moss, 1996). High academic load systematically causes time constraints on the students, especially in completing specific academic tasks or activities (Guo et al., 2011; Koh, Scully, \& Woodliff, 2011). This is further confounded by complex educational assessment, which conceptually refers to a specific assessment structure as an objective medium to measure student performance. Students' performance is commonly assessed through various evaluation techniques such as continuous quizzes, test presentations, and reports. Clift and Thomas (1983) reported these (cited in Kadapatti and Vijayalaxmi (2012) as significant sources of students' stress.

\subsection{Early submission of activities and assessment}

Early submission of activities and assessments was cited by participant four as a source of her stress during the pandemic. This is supported by participant number four's statement. Submission of activities and assessments, she believes, is too early. Instead of providing them more time to complete the activities, the instructors told them to complete the given tasks as soon as the next day.

\section{Participant 4:}

The submissions to requirements and activities are too early. Instead of giving as enough time, they will tell to pass the next day.

She also mentioned that the course topic is complex in and of itself and that they would need adequate time to search for and read other resources in addition to the learning materials provided. Because they only had a small amount of time to complete the exercise, they had to rush it, which caused her stress.

Based on the research findings of Rotas et al. (2020), the students expressed overloaded lesson activities. As they mentioned, a teacher would require almost three activities in a subject, thus giving them less time to answer them all carefully. This difficulty in remote learning has been confirmed in Sundarasen et al.'s (2020) study, where university students in Malaysia expressed stress about the overwhelming number of assignments required by the teachers. Their findings also revealed that this difficulty had a huge impact on the stress and anxiety levels of the students. The same experience was also reported by Sarvestani et al. (2019), where students complained about the extensive volume and many modules they needed to answer. In addition, a high academic load systematically causes time constraints on the students, especially in completing specific academic tasks or activities (Guo, 2011; 
Koh, Scully, \& Woodliff, 2011). Moreover, the early submission of activities and assessments created pressure on the part of the students. Additionally, when questioned about her stressors during the epidemic, participant 6 stated academic pressure as one of her biggest worries. Academic pressure and the expectations of those around her are the number one source of stress for participant 6 . People are expecting a lot from her, she continued.

\section{Participant 6:}

Academic pressure is my number 1 stressor.

Moreover, to stay in the program, she believes she must perform well. She added that the Bachelor of Science in Accountancy program demands significant study time and effort. Academic pressure is formally described as a situation in which a student is burdened by time and energy demands to meet particular educational objectives (Durrette 2020). This pressure can originate from many places and have a wide range of emotional and academic consequences for students.

\subsection{Hardly have a response from instructors}

As indicated by the participant, the lack of immediate response from instructors caused delays in submitting activities, causing stress. There have been instances when they have questions about the courses in the module. Then, they need to ask and clarify them with the instructor, but the instructor has failed to respond to their messages. It is supported by the response below:

\section{Participant 7:}

My instructors hardly responded to my question regarding the topics in the module or about the given tasks. It had a significant impact because it affected my work.

Supporting this claim is the study conducted by Rotas et al. (2020) which revealed that gaining teacher support is essential for students' learning. However, it is still a difficulty for the students surveyed, thus resulting in limited teacher scaffolds. At times, teachers' expectations from students can be hard to meet, which makes them hard to approach. This difficulty could also be affiliated with the fact that some universities do not have a proper functioning e-learning operations system designed to support students with online library materials and a learning support system (Kerres, 2020). These may be available, but teachers also had challenges operating the system and facilitating online teaching (Zhang, Wang et al., 2020), thus making it hard for students. Just like on-campus learning, remote learning also needs social interaction and the exchange of ideas.

In addition to that, the teachers' characteristics should also be a concern to the university. Lecturers' characteristics, which have not been studied previously, have been proved to affect students' learning 
activities, consequently building the presence of stress among the students (Pluut, Curşeu, \& Ilies, 2015). It is essential for universities to adequately address the issue of students-lecturers relationship so that it would be the stress situation and the students' performance. Teachers' amount of guidance and support may also determine student stress (Abouserie, 1994; Meijer, 2007).

\section{Psychological Stressor}

The psychological stressor is the third sub-theme as presented in the table above, and under this subtheme is (a) Lack of self-discipline. This was based on the code generated in the transcript.

\subsection{Lack of Self-Discipline}

\section{Participant 2:}

During the pandemic, I excessively used Facebook and online games. I spent a lot of time on it to the point that I sacrificed my time for study.

According to participant two, she spent a lot of her time on Facebook and played online games like Mobile Legends throughout the pandemic. She doesn't have time to study because of her excessive use of social media sites like Facebook and online games like Mobile Legends.

A research study self-discipline as a critical indicator to improve learning outcomes in an e-learning environment by Gorbunovs et al. (2016) stated that self-discipline positively impacts learning outcomes. Achievements at the end of the learning course do not depend on students' initial competence levels. Contrariwise, self-discipline is the key factor that influences learners and allows them to achieve their primary goals. Accordingly, self-discipline in the daily routine knowledge acquisition process is the key indicator to improve learning outcomes.

Table 4 Coping Strategies Adopted

\begin{tabular}{ll}
\hline Factors & Responses \\
\hline Task-oriented coping & $\begin{array}{l}\text { Use two different networks to double data in } \\
\text { case of an unstable internet connection } \\
\text { strategy }\end{array}$ \\
& $\begin{array}{l}\text { Observe Time Management } \\
\text { Learn to adjust to the surrounding } \\
\text { Find other ways to contact instructors. }\end{array}$ \\
& \\
Emotion-oriented & Self-realization \\
coping strategy & Self-meditation \\
& Self-motivation \\
\hline
\end{tabular}


The table above depicts the coping strategies adopted by BS-Accountancy students. The first theme discusses the stresses faced by students during the pandemic. This second theme is currently focusing on the strategy used by students to cope with perceived stress. This is divided into two sub-themes: (1) Task-oriented Coping Strategies and (2) Emotion-oriented Coping Strategies. 1. Task-oriented Coping Strategies.

As defined in the study of Kariv and Heiman (2005) entitled Task-Oriented Versus Emotion-Oriented Coping Strategies: The Case of College Students, the task-oriented strategy is problem-focused. It involves taking direct action to alter the situation itself to reduce the amount of stress it evokes. Moreover, this sub-theme is divided into (a) Use two different networks to double data in case of unstable internet connection (b) Observe time management (c) Learn to adjust to the surrounding (d) Find other ways to contact instructors.

\subsection{A Use two different networks to double data in case of an unstable internet connection}

One of the identified stresses of the participants of the study is the unstable internet connection. They answered that they need to use two different networks to double data when unstable internet connection.

\section{Participant 1:}

How should I cope-up with my stressors? What I did is I double my data for a better internet connection. I used mobile data and WIFI in case the other will have internet connection loss.

According to participant one, his one way of coping with an unstable internet connection is double his mobile Data and Wireless Fidelity (WIFI) resources. When one network malfunctions, he has the other one to continue his activities. This was supported by respondent seven.

\section{Participant 7:}

In my internet connection problem, if there is a public advisory for system repairs that might affect the internet connection, I subscribed to other networks to continue my tasks and activities online.

She said that when the internet connection of a specific network became temporarily unavailable, as announced on their websites, she used another network to keep active online. Michigan State University's Quello Center 2021, slow Internet connections, or limited access from rural areas can contribute to students falling behind academically. Academic failure, college admissions, and professional chances can all be negatively impacted by educational setbacks resulting in stress to students. This is evidence that a strong internet connection is essential in this modular distance learning. 
Students who have access to the Internet, according to Price and Brouwer (2020), can keep up with the knowledge that may not be included in textbooks or may become outdated by the time it is published traditionally. Access to this information allows students to take ownership of their education, as evidenced by a study; other studies found that when students could use technology to assist them with their studies, discipline concerns dropped.

With the help of the Internet, they can communicate with international students; they can make student groups and share their knowledge, ideas, and experiences. Also, they can learn about the many diverse cultures out there. The Internet provides them with a great platform to learn anything at anytime and anywhere.

\subsection{Observe Time Management}

The majority of the participants answered having time management is their coping strategy to academic stressors, as stated in the table above. This is evidenced by their statements below.

\section{Participant 5:}

First and foremost, I make sure that I have time for my personal life leisure to enjoy. I make sure that my time is well allocated for personal and school stuff to avoid cramming or procrastination. I also plan ahead of time.

According to participant five, to cope with his stressors, he makes sure that he has time to have both study-related activities and personal leisure time. Everything is set and organized to eliminate or prevent himself from cramming or procrastinating. Additionally, he plans everything ahead of time. Respondent four also stated:

\section{Participant 3:}

Since we are studying online, I downloaded applications that I can use for time management. For example, I used Google calendar that will notify and remind me of my scheduled activities. I thoroughly divide my time for socialization, school, rest, and other essential things.

He added that his tool in managing his time is to download a Google calendar wherein he can schedule things ahead of time to make sure that he has time to study, socialize with his friends, visit social media, read books, and rest.

\section{Participant 3:}

In my academic stress, whenever I hardly relate or understand the topic written in the module, I pause 
and rest for a bit. When I'm okay and ready to resume, I continue, and I think it is time management to keep on track.

Moreover, another participant added that time management is his way of coping with stress. Whenever he hardly understood topics in his course, he took a break, like listening to music and playing online games like a mobile legend. Afterward, when his stress was relieved, he went back and continued and focused on his study.

\section{Participant 9:}

I also learn to plan my things ahead of time to avoid procrastination (but old habits die hard) and enjoy the pace while struggling.

Furthermore, one way for the participant to manage time is to monitor the schedule of the passing of requirements to keep on track. The statement from participants 6 , six supports this.

\section{Participant 6:}

I really monitored my activities. If ever it pop-up on my Google classroom, I immediately do it so that the next day, I can pass it even if it is not the due date.

She monitors the posting of activities to pass them as early as the next day.

\section{Participant 7:}

Time management. Since I admit that I am a procrastinator, I applied time management.

And also, participant seven shared the same thing with the other respondent. She admitted that she is a procrastinator. Therefore, he uses the same strategy-time management. As studied by Taylor and Owusu-Banahene, (2010), college students' time management: Correlations with academic performance and stress, many college students may find the educational experience very stressful (Swick, 2010). One potential coping strategy frequently offered by university counseling services is time management. The Time Management Behavior Scale consists of 4 relatively independent factors; the most predictive was Perceived Control of Time. Students who perceived control of their time reported significantly greater performance evaluations, more excellent work and life satisfaction, less role ambiguity, less role overload, and fewer job-induced and bodily tensions. Findings are consistent with theory and advice on time management (Schuler, Musekamp, et al. 2013).

More so, it is duly supported by the study of Misra and Mckean (2000) that time management has a more significant buffering effect on academic stress and poor time management is a predictor of 
academic stress. Ilies, Johnson, Judge, et al. (2011) identified organization of time as one of the critical stressors of student hood. Moreover, knowing your study habit is an effective way of coping with stress. According to the first respondent, it is more efficient for him the study at dawn. He added that there are no distractions like noise if you study at dawn, and he learns more.

\section{Participant 1:}

I prefer to study early in the morning because I can quickly learn the topics compared to other times of the day where there are so many distractions.

Van de Pol, Volamn (2011) cited Marc (2011) eloquently stated that it is crucial for every student irrespective of his level of education, as it boosts students' ability to be self-disciplined, self-directed, and ultimately successful in their degree programs. He further maintained that effective study habits are an essential part of the learning process.

\subsection{Learn to Adjust to the Surrounding}

One way of coping with stress brought by the pandemic affects the learning process, and a response answered that learning to adjust to the situation is her coping strategy.

\section{Participant 4:}

What I did was adjust to the environment. If I have upcoming exams, I inform informed members immediately to be aware of the situation and do things to distract me.

I'm simply getting used to the new surroundings. If I ever have exams, I'll let my nephews know ahead of time, so they don't raise a fuss or don't play at home and instead go somewhere safe to play. Otherwise, I'd study at our other house. Because we can't fully control the circumstances and there isn't another appropriate area to learn, I'm the only one who will adjust. According to Hendrix (2019), learning environments are critical to student performance. Seating, light, noise, and even color can all have an impact on learning ability. Students who learn in a good setting are more motivated, engaged, and have better overall learning abilities. Students learning under unfavorable conditions, such as uncomfortable, noisy, or full of distractions, will have a significantly tougher difficulty processing information and being engaged. Let's look at how your surroundings influence your study habits and evaluate some of the best ways to design your perfect learning environment with this in mind. Some people learn better with background noise, while others work best in perfect stillness.

\subsection{Find Other Ways to Contact Instructors.}

One of the identified stressors of participants is that they can hardly respond to instructors whenever they have questions and clarifications regarding their activities and assessments. 


\section{Participant 7:}

For my instructors, what I did was try and wait for them to respond. If they are unavailable, I tried to look for other ways to contact them, like using their mobile number.

According to participant seven, what he did was if the instructors were unavailable, he waited until they were active online. Otherwise, he will contact them in a way possible, like their cellphone numbers. A study conducted by Conklin and Dikkers (2021) of the University of North Carolina Wilmington, Instructor Social Presence and Connectedness in a Quick Shift from Face-to-Face to Online Instruction, student responses on open- and closed-ended questions supported the importance of feeling connected to their instructor, class, and classmates. When asked to rank methods of communication in terms of volume to their learning and motivation-including text announcements, video announcements, course emails, or a mix of text and video-most students (67\%) ranked course emails as most important.

Furthermore, according to a study, conversing with professors makes you feel more at ease in college and more connected to the institution. Students who communicate with their professors are less likely to grow disillusioned and abandon their studies. Students who connected with their teachers were often obtained valuable comments, gained insight into how to approach their course work, and build confidence in general. According to research, students who feel linked to their college's instructors and staff are more able to adhere to their academics and earn a degree. Professors are an excellent resource for learning more about a subject. Most teachers will provide you with guidance and information on choosing a major or potential career in their sector.

\section{Emotion Oriented Copy Strategy}

An adverse emotion-focused coping strategy addresses negative emotional reactions to stress such as anxiety, fear, sadness, and anger. When a stressor is something you can't change, this type of coping might be helpful. This sub-theme focuses on the emotion-oriented coping strategy and is divided into (a) Self-realization, (b) Self-motivation, and (c) Self-meditation.

\subsection{Self-Awareness}

Respondents stated that one way of coping up with her stressor is to realize his situation. Her statement supports this.

\section{Participant 2:}

Eventually, I realized that I needed to do something to be productive. I did nothing that would make my situation better. I tried to distance myself from social media, and I quit playing mobile games for 
months. That's what I did to help myself cope up with my stressors.

She eventually understood that things were not going well for her. She has yet to take any steps to improve her condition. For the past few months, she has attempted to deactivate Facebook and remove some of the installed mobile game apps to concentrate on her schoolwork. According to the study of Anna Sutton 2016, measuring the Effects of Self-Awareness: Construction of the Self-Awareness Outcomes Questionnaire Self-awareness has long been seen by practitioners and researchers as both a primary means of alleviating psychological distress and the path of self-development for psychologically healthy individuals. Recently an extensive review has demonstrated that different aspects of self-awareness, including mindfulness and rumination, mediate the impact of mindfulnessbased interventions on mental health outcomes (Gu, Strauss, Bond, \& Cavanagh, 2015). The importance of self-awareness goes beyond well-being and mental health to include substantial impacts on day-to-day functioning. It has essential effects on performance, with reflection and mindfulness encouraging persistence with tasks despite performance-related stress (Feldman, Dunn, Stemke, Bell, \& Greeson, 2014) and rumination related to interpersonal difficulties (Brinker, Chin, \& Wilkinson, 2014).

\subsection{Self-motivation}

One identified coping strategy applied by some respondents to overcome their stressors is selfmotivation.

\section{Participant 6:}

We all experience stress, especially in this time of the pandemic. We have our stressors, but it depends on the person how to handle them. I just embraced it and kept going. I build a positive mindset that whatever I am encountering right now, I will overcome it.

According to her, the first step in motivating herself is acknowledging that this is the actual reality and stressful - accepting that we all have our stressors, particularly amid the pandemic. Now it's up to you to decide how you'll deal with it. I've become acclimated to the scenario; therefore, I've motivated myself to go through it all. According to the study Academic Stress, Academic Motivation, and Its Relationship on the Academic Performance of the Senior High School Students 2020, motivation is another factor that can affect academic performance (Hajisabbagh, Fereidooni-moghadam, et al. 2019). Academic achievement is influenced by motivation (Dogan, 2017).

As a result, motivation is critical to academic success. The higher academic achievement follows higher motivation (Kori et al., 2016). As a result, motivation is likely to have a strong link to academic performance. Student involvement, academic self-efficacy, and academic motivation were found to 
affect the extent to which academic performance was altered in a study conducted by Dogan (2017). According to the findings, cognitive involvement predicts academic success but not emotional or behavioral engagement. Furthermore, academic motivation and self-efficacy have a positive and meaningful link with academic achievement. A similar study was conducted by Çetin (2015). It was determined whether academic motivation and academic self-regulated learning are predictors of students' GPAs in the Early Childhood Education Department.

\subsection{Self-Meditation}

Self-meditation is an effective way of coping with stress during this pandemic.

\section{Participant 9:}

Honestly, I struggled more since the pandemic started. I became more distracted, anxious, and selfdeprecating. Still, I am struggling since everything is limited because of the pandemic and the pressure. I am under because of the program I am currently enrolled in. However, I always look for a silver lining in everything; hence, I applied those coping strategies by distancing myself and meditating. I also seek and pray to God in everything.

According to Scott-Young, Turner, and Holdsworth (2020), people who meditate regularly show changes in their stress response, helping them recover more rapidly from stressful experiences and experience less stress from the challenges they face in their daily lives. Some of this is likely due to meditation's improved positive mood; research shows that those with more positive attitudes are more robust to stress. Other studies have discovered changes in the brains of regular meditation practitioners that are associated with a reduction in stress reactivity. When you learn to refocus your thoughts, you may help yourself relax by diverting your thoughts when you're engaged in a negative thought pattern.

\subsection{CONCLUSION}

The study is primarily administered to determine the stressor and coping strategy of the JRMSU-Main campus accountancy students during the COVID-19 pandemic. This is answered by conducting a virtual interview. Based on the above findings, the researchers concluded that accountancy students of JRMSU-Main Campus had various stressors that contributed to their stress during the COVID-19 pandemic. Environmental stressors, which are categorized as (1) unstable internet connection, (2) family activities and problems, and (3) isolation due to health protocols, were stated by the respondents as one of their stressors. The result also shows that academic stressors such as (1) Modular Distant Learning - there is no face-to-face discussion, (2) early submission of activities and assessment, and (3) lack of immediate response from instructors contributes to students' stress. For psychological stressors, (1) lack of self-discipline is identified as students' stressor. 
The above findings also divulge the coping strategies adopted by students, which included taskoriented coping strategy specifically (1) using two different networks to double data in case of unstable internet connection (2) observing time management (3) learning to adjust to the surrounding (4) find another way to contact instructors and emotion-oriented coping strategy specifically (1) selfrealization (2) self-meditation (3) self-motivation.

Collectively, the COVID-19 pandemic has contributed burdens to the lives of students. The shift of the traditional learning model to the flexible learning system and the sudden health restrictions with the environment are significant sources of stress to students. Teaching and learning have become more challenging as students have different experiences on their stressors and coping with such difficulties. In general, the study supports Lazarus and Folkman's (1984) Transactional Theory of Stress and Coping, which views stress as the result of a transaction between a person (containing many systems: cognitive, physiological, affective, psychological, and neurological) and their complex environment. This confirms that the environment plays a vital role in the students' performance, specifically in this pandemic. The pandemic (environment) brought challenges that constitute a stress to students. Similar to the above theory, the accountancy students, when faced with challenges, recognize that the situation was stressful and affects them negatively and then adopt coping strategies to fight against stressors.

\subsection{RECOMMENDATIONS}

The school should conduct seminars about Stress Management for students and parents of Jose Rizal Memorial State University-main Campus. This will help students manage their stress, especially amid the Pandemic. This also promotes parental involvement in students' situations for them to understand and help their children. The Supreme Student Government should create activities where they can help students express themselves to reduce their stress.

The student needs to find other sources of knowledge that will assist them in having a more in-depth discussion by locating other authors who can help them better comprehend the challenging section of the subject. Since there is no physical discussion, students can also watch YouTube tutorials or ask higher-level students in the same program or acquaintances who are well-versed in the field. Students need to be responsible for their tasks, be aware of due dates, and do the teacher-given jobs immediately to avoid cramming.

Students should make a schedule that will allow them to manage their schoolwork and other activities more effectively. They have something to anticipate each day, even if it isn't necessary. This provides you a reason to look forward to the next day, which helps deal with academic stress easier. Students should avoid having unreasonable expectations. Teachers should have time to respond to student's queries or ask questions regarding their modules. When they are unable to reply, they should have a 
specified date to accommodate students' concerns.

On the other hand, students must approach their teachers formally within office hours. Students must be explicit about the things they want to perform each day. After completing almost scheduled tasks, he must be productive daily by doing activities distant from the deadline.

\subsection{REFERENCES}

Abouserie, R. (1994). Sources and levels of stress in relation to locus of control and self esteem in university students. Educational psychology, 14(3), 323-330.

Ahmadi, F., Khodayarifard, M., Zandi, S., Khorrami-Markani, A., Ghobari-Bonab, B., Sabzevari, M., \& Ahmadi, N. (2018). Religion, culture and illness: A sociological study on religious coping in Iran. Mental Health, Religion \& Culture, 21(7), 721-736.

Aboagye, E., Yawson, J. A., \& Appiah, K. N. (2021). COVID-19 and E-learning: The challenges of students in tertiary institutions. Social Education Research, 1-8.

Ahmadi, F., Khodayarifard, M., Zandi, S., Khorrami-Markani, A., Ghobari-Bonab, B., Sabzevari, M., \& Ahmadi, N. (2018). Religion, culture and illness: A sociological study on religious coping in Iran. Mental Health, Religion \& Culture, 21(7), 721-736.

Amadora, M. G. (2020). Common Problems that Occur During Online Classes.

Amali, I., Bello, M. B., \& Adeoye, G. O. (2018). Influence of domestic works on female students academic performance in upper-basic schools in Kwara State, Nigeria. Journal of Education in Developing Areas, 26(1), 196-202.

Amirkhan, J., \& Auyeung, B. (2007). Coping with stress across the lifespan: Absolute vs. relative changes in strategy. Journal of Applied Developmental Psychology, 28(4), 298-317.

Baticulon, R. E., Sy, J. J., Alberto, N. R. I., Baron, M. B. C., Mabulay, R. E. C., Rizada, L. G. T., ... \& Reyes, J. C. B. (2021). Barriers to online learning in the time of COVID-19: A national survey of medical students in the Philippines. Medical science educator, 31(2), 615-626.

Bernama (2015, May 25). Malaysia Needs 60,000 Accountants by 2020. New Straits Times. Retrieved from https://www.nst.com.my/news/2015/09/malaysia-needs-60000accountants-2020. 
Vol. 3, No. 06 Nov-Dec; 2021 Page. No. 145-173

Beiter, R., Nash, R., McCrady, M., Rhoades, D., Linscomb, M., Clarahan, M., \& Sammut, S. (2015). The prevalence and correlates of depression, anxiety, and stress in a sample of college students. Journal of affective disorders, 173, 90-96.

Biggs, A., Brough, P., \& Drummond, S. (2017). Lazarus and Folkman's psychological stress and coping theory. The handbook of stress and health: A guide to research and practice, 351-364.

Bond, F. W., \& Bunce, D. (2000). Mediators of change in emotion-focused and problemfocused worksite stress management interventions. Journal of occupational health psychology, 5(1), 156.

Braun, V., \& Clarke, V. (2006). Using thematic analysis in psychology. Qualitative research in psychology, 3(2), 77-101.

Bruhn, J. G., Zajac, G., Al-Kazemi, A. A., \& Prescott Jr, L. D. (2002). Moral positions and academic conduct: Parameters of tolerance for ethics failure. The Journal of Higher Education, 73(4), 461-493.

Burgess, S., \& Sievertsen, H. H. (2020). Schools, skills, and learning: The impact of COVID19 on education. VoxEu. org, 1(2).

Brinker, J. K., Chin, Z. H., \& Wilkinson, R. (2014). Ruminative thinking style and the MMPI2-RF. Personality and Individual Differences, 66, 102-105.

Carveth, J. A., Gesse, T., \& Moss, N. (1996). Survival strategies for nurse-midwifery students. Journal of Nurse-Midwifery, 41(1), 50-54.

Cetin, B. (2015). Academic motivation and self-regulated learning in predicting academic achievement in college. Journal of International Education Research, 11(2), 95-106.

Chang, C. L., \& Fang, M. (2020, June). E-Learning and online instructions of higher education during the 2019 novel coronavirus diseases (COVID-19) epidemic. In Journal of Physics: Conference Series (Vol. 1574, No. 1, p. 012166). IOP Publishing.

Chen, N., Zhou, M., Dong, X., Qu, J., Gong, F., Han, Y., \& Zhang, L. (2020). Epidemiological and clinical characteristics of 99 cases of 2019 novel coronavirus pneumonia in Wuhan, China: a descriptive study. The lancet, 395(10223), 507-513.

Conklin, S., \& Dikkers, A. G. (2021). Instructor Social Presence and Connectedness in a Quick Shift from Face-to-Face to Online Instruction. Online Learning, 25(1), 135-150.

Dogan, U. (2015). Student engagement, academic self-efficacy, and academic motivation as 
predictors of academic performance. The Anthropologist, 20(3), 553-561.

Durrette, C. (2020, February 5). Academic Pressure from Family, Society Takes Toll on Students. The daily Cougar. Retrieved from www.thedailycougar.com

Feldman, G., Dunn, E., Stemke, C., Bell, K., \& Greeson, J. (2014). Mindfulness and rumination as predictors of persistence with a distress tolerance task. Personality and individual differences, 56, 154-158.

Folkman, S., \& Lazarus, R. S. (1988). Coping as a mediator of emotion. Journal of personality and social psychology, 54(3), 466.

Gabre, H., \& Kumar, G. (2012). The effects of perceived stress and Facebook on accounting students' academic performance. Accounting and Finance Research, 1(2), 87-100.

Ginosyan, H., Tuzlukova, V., \& Hendrix, T. (2019). Teachers' perspectives on extra-curricular activities to enhance foundation program language learners' academic and social performances. Journal of Applied Studies in Language, 3(2), 168-177.

Gorbunovs, A., Kapenieks, A., \& Cakula, S. (2016). Self-discipline as a key indicator to improve learning outcomes in e-learning environment. Procedia-Social and Behavioral Sciences, 231, 256-262.

Gu, J., Strauss, C., Bond, R., \& Cavanagh, K. (2015). How do mindfulness-based cognitive therapy and mindfulness-based stress reduction improve mental health and wellbeing? A systematic review and meta-analysis of mediation studies. Clinical psychology review, 37, 1-12.

Guo, Y. J., Wang, S. C., Johnson, V., \& Diaz, M. (2011). College students' stress under current economic downturn. College Student Journal, 45(3), 536-544.

Gruen, R. J., Folkman, S., \& Lazarus, R. S. (1988). Centrality and individual differences in the meaning of dally hassles. Journal of Personality, 56(4), 743-762.

Hajisabbagh, N., Fereidooni-Moghadam, M., \& Etemadifar, M. (2019). Coping strategies and their relationship with emotional intelligence in patients with epilepsy referred to Isfahan Epilepsy Society in 2017. Epilepsy \& Behavior, 92, 200-205.

Hammer, L. B., Bauer, T. N., \& Grandey, A. A. (2003). Work-family conflict and work-related withdrawal behaviors. Journal of Business and Psychology, 17(3), 419-436.

How, Z. J., Shinde, J. S., \& Willems, J. (2013). Academic stress in accounting students: An empirical study. Asian Journal of Accounting and Governance, 4, 1-10. 
Ilies, R., Johnson, M. D., Judge, T. A., \& Keeney, J. (2011). A within-individual study of interpersonal conflict as a work stressor: Dispositional and situational moderators. Journal of Organizational Behavior, 32(1), 44-64.

Kadapatti, M. G., \& Vijayalaxmi, A. H. M. (2012). Stressors of academic stress-a study on preuniversity students. Indian Journal of Scientific Research, 3(1), 171-175.

Kariv, D., \& Heiman, T. (2005). Task-oriented versus emotion-oriented coping strategies: The case of college students. College Student Journal, 39(1), 72-85.

Kapasia, N., Paul, P., Roy, A., Saha, J., Zaveri, A., Mallick, R., ... \& Chouhan, P. (2020). Impact of lockdown on learning status of undergraduate and postgraduate students during COVID-19 pandemic in West Bengal, India. Children and Youth Services Review, 116, 105194.

Kerres, M. (2020). Against all odds: Education in Germany coping with Covid-19. Postdigital Science and Education, 2(3), 690-694.

Koh, H. P., Scully, G., \& Woodliff, D. R. (2011, September). The impact of anticipation on accounting students ethical decision making under time pressure. In 5th Asia Pacific Conference on Educational Integrity, The University of Western Australia (pp. 26-28).

Kwaah, C. Y., \& Essilfie, G. (2017). Stress and coping strategies among distance education students at the University of Cape Coast, Ghana. Turkish Online Journal of Distance Education, 18(3), 120-134.

Lazarus, R. S., \& Folkman, S. (1987). Transactional theory and research on emotions and coping. European Journal of personality, 1(3), 141-169.

Meijer, J. (2007). Correlates of student stress in secondary education. Educational Research, 49(1), 21-35.

Misra, R., \& McKean, M. (2000). College students' academic stress and its relation to their anxiety, time management, and leisure satisfaction. American journal of Health studies, 16(1), 41.

Myers, A. M., \& Rothblum, E. D. (2005). Coping with prejudice and discrimination based on weight. The psychology of prejudice and discrimination: Disability, religion, physique, and other traits, 4, 112-134.

Nor, M. N. M., Nahar, H. S., Alrazi, B., \& Taha, R. (2019). Stress Among accounting students: A Preliminary study of Malaysian Universities. Journal of Business and Social 
Development, 7(1), 9-19.

Obbarius, N., Fischer, F., Liegl, G., Obbarius, A., \& Rose, M. (2021). A Modified Version of the Transactional Stress Concept According to Lazarus and Folkman Was Confirmed in a Psychosomatic Inpatient Sample. Frontiers in psychology, 12, 405.

Pluut, H., Curşeu, P. L., \& Ilies, R. (2015). Social and study related stressors and resources among university entrants: Effects on well-being and academic performance. Learning and Individual Differences, 37, 262-268.

Poncian, P. (2017). The impact of home environment on students' academic achievement in Tanzanian secondary schools: A case of Geita Town Council (Doctoral dissertation, The University of Dodoma).

Price, R. A., \& Bijl-Brouwer, M. V. D. (2020). What motivates our design students during COVID-19?. Journal of Design, Business \& Society, 7(2), 233-249.

Uehara, T., Takeuchi, K., Kubota, F., Oshima, K., Ishikawa, O. (2010). Annual Transition of Major Depressive Episode in University Students using a Structured Self-rating Questionnaire. Asia-Pacific Psychiatry 2, 99-104.

Oyewobi, L. O., Bolarin, G., Oladosu, N. T., \& Jimoh, R. A. (2020). Influence of stress and coping strategies on undergraduate students' performance. Journal of Applied Research in Higher Education.

Rajkumar, R. P. (2020). COVID-19 and mental health: A review of the existing literature. Asian journal of psychiatry, 52, 102066.

Reddy, K. J., Menon, K. R., \& Thattil, A. (2018). Academic stress and its sources among university students. Biomedical and Pharmacology Journal, 11(1), 531-537.

Rotas, E. E., \& Cahapay, M. B. (2020). Difficulties in Remote Learning: Voices of Philippine University Students in the Wake of COVID-19 Crisis. Asian Journal of Distance Education, 15(2), 147-158.

Santos, M. A., Munoz, R., Olivares, R., Reboucas Filho, P. P., Del Ser, J., \& de Albuquerque, V. H. C. (2020). Online heart monitoring systems on the internet of health things environments: A survey, a reference model and an outlook. Information Fusion, 53, 222-239.

Savage, S., \& Bailey, S. (2004). The impact of caring on caregivers' mental health: a review of the literature. Australian health review, 27(1). 
Schuler, M., Musekamp, G., Faller, H., Ehlebracht-König, I., Gutenbrunner, C., Kirchhof, R., \& Schwarze, M. (2013). Assessment of proximal outcomes of self-management programs: translation and psychometric evaluation of a German version of the Health Education Impact Questionnaire (heiQ ${ }^{\mathrm{TM}}$ ). Quality of life research, 22(6), 1391-1403.

Scott-Young, C. M., Turner, M., \& Holdsworth, S. (2020). Male and female mental health differences in built environment undergraduates. Construction Management and Economics, 38(9), 789-806.

Steel, A., Diezel, H., Wardle, J., \& Adams, J. (2020). Working with women: Semi-structured interviews with Australian complementary medicine maternity cares practitioners. Women and Birth, 33(3), e295-e301.

Sundarasen, S., Chinna, K., Kamaludin, K., Nurunnabi, M., Baloch, G. M., Khoshaim, H. B., \& Sukayt, A. (2020). Psychological impact of COVID-19 and lockdown among university students in Malaysia: implications and policy recommendations. International journal of environmental research and public health, 17(17), 6206.

Swick, K. J. (2010). Responding to the voices of homeless preschool children and their families. Early Childhood Education Journal, 38(4), 299-304.

Tandon, R. (2020). COVID-19 and mental health: preserving humanity, maintaining sanity, and promoting health. Asian journal of psychiatry, 51, 102256.

Taylor, M. E., \& Owusu-Banahene, N. O. (2010). Stress among part-time business students: A study in a Ghanaian university campus. IFE PsychologIA: An International Journal, 18(1), 112-129.

Van de Pol, J., Volman, M., \& Beishuizen, J. (2011). Patterns of contingent teaching in teacherstudent interaction. Learning and Instruction, 21(1), 46-57.

Williams, E. S., Konrad, T. R., Scheckler, W. E., Pathman, D. E., Linzer, M., McMurray, J. E., \& Schwartz, M. (2010). Understanding physicians' intentions to withdraw from practice: the role of job satisfaction, job stress, mental and physical health. Health care management review, 35(2), 105-115.

Yusoff, M. S. B. (2010). Stress, stressors and coping strategies among secondary school students in a Malaysian government secondary school: Initial findings. ASEAN Journal of Psychiatry, 11(2), 143-157.

Zhang, W., Wang, Y., Yang, L., \& Wang, C. (2020). Suspending classes without stopping learning: China's education emergency management policy in the COVID-19 outbreak. 